\title{
Effective ionic-liquid microemulsion based electrodeposition of mesoporous Co-Pt films for methanol oxidation catalysis in alkaline media
}

\author{
Albert Serrà,a Elvira Gómez,a Igor V. Golosovsky,b Josep Nogués,c,d and Elisa Vallésa \\ ${ }^{a}$ Grup d'Electrodeposició de Capes Primes i Nanoestructures (GE-CPN), Departament de \\ Química Física and Institut de Nanociència i Nanotecnologia (IN $\left.{ }^{2} U B\right)$, Universitat de \\ Barcelona, Martí i Franquès 1, E-08028, Barcelona, Catalonia, Spain. \\ ${ }^{b}$ Catalan Institute of Nanoscience and Nanotechnology (ICN2), CSIC and The Barcelona \\ Institute of Science and Technology, Campus UAB, Bellaterra, 08193 Barcelona, Spain. \\ ${ }^{c}$ ICREA - Institució Catalana de Recerca i Estudis Avançats, Barcelona, Catalonia, Spain.
}

\begin{abstract}
Pt-based direct methanol fuel cells are attracting increasing interest as environmentally friendly alternativeenergy sources. However, the high price of $\mathrm{Pt}$ and the difficulty to prepare favourable morphologies for catalysis (e.g., mesoporous materials) are hampering their development into feasible products. Here, we demonstrate a novel approach to efficiently grow mesoporous films of Pt-poor alloys (Co3Pt and $\mathrm{CoPt} 3)$, based on electrodeposition in ionic liquid-in-water (IL/W) microemulsions. The high proportion of the electrolytic aqueous solution in the IL/W microemulsion favors a significant deposition rate, while the presence of IL drops induces the formation of highly mesoporous films. The mesoporous alloys, with pores in the $8-11 \mathrm{~nm}$ range, exhibit excellent durability in acidic and alkaline aggressive media, maintaining their peculiar morphology. The structures are very efficient for the catalysis of methanol electro-oxidation in alkaline media, with minimal poisoning of the catalysts. These results pave the way to develop simple, versatile environmentally friendly fuel cell catalysts to commercialize new viable ecological alternative energy sources.
\end{abstract}

\section{Introduction}

The threat of global warming is generating a growing social and scientific interest in alternative ecological energy sources toreduce the use of contaminating fossil fuels.1,2 In this context, fuel cells have recently received tremendous attention as a future energy technology, 
since they can convert chemical energy directly into electrical energy using environmentally friendly processes with high energy conversion efficiencies.3-6 In particular, Direct Methanol Fuel Cells (DMFCs) are especially appealing due to their outstanding advantages, such as high power density, environmental friendliness, simplicity, ease of recharging, and low operating temperatures.7-9 However, the high cost and the short lifespan of Pt, which has been recognized as the best catalyst toward methanol oxidation, present a major technical challenge, slowing down the progress of fuel cell commercialization.10-12 Therefore, it is essential to explore new efficient Pt-free or Pt-poor catalysts with enhanced activity, stability and durability (especially in basic media, since both methanol oxidation and oxygen reduction reactions are faster in alkaline media than in the presence of acidic electrolytes).13-15 To reduce or replace Pt, a wide range of active and inexpensive nonprecious catalysts, including transition metals, 16,17 transition metal chalcogenides, 18,19 metal oxides,20-22 nitrogen-coordinated complexes, and conductive polymers, 23 among others, are being actively investigated. Another appealing strategy to effectively enhance the activity and to reduce the costs is the incorporation of other metals into platinum nanostructures (e.g., AuPt and PdPt).24,25 In particular, Co-Pt structures have been introduced as a possible future electrocatalyst due to their excellent performance and the low cost of Co compared to that of $\mathrm{Pt}$, $\mathrm{Au}$ or $\mathrm{Pd}$, although the composition of the alloy is critical in determining the durability of Co-Pt nanostructures when they are used as electrocatalysts for DMFCs in acidic media.9,26 However, one of the most promising schemes to boost the performance of electrocatalysts and to reduce the load of $\mathrm{Pt}$ in devices is combining the above approaches with the use of a porous morphology (especially mesoporous) with a high surface area.27,28 The development of mesoporous materials has attracted great interest in the past few years due to their unique properties which have led to multiple applications in very diverse elds (e.g., catalysis, sensors, solar cells, adsorbents or drug delivery).29-33 The traditional approaches for synthesizing mesoporous structures are based on surfactant/block copolymerso $\square$-templating, hard-templating or colloidal crystal templating.34-37 Recently, so-template systems have also been used as electrochemical media for preparing mesoporous structures by means of electrodeposition. Interestingly, different electrochemical media have been proposed for this purpose (although each of them presents some shortcomings): (i) ionic liquids, which are overly viscous for preparing nanomaterials,35,36,38 (ii) surfactant micelles, although this method only allows the preparation of a limited number of metals3942 and (iii) water-in ionic liquid (W/IL) microemulsions, which usually implies low efficiencies and extremely long deposition times.43,44 Therefore,given the drawbacks and 
limitations of the current approaches to synthesize mesoporous structures by electrodeposition, exploring new electrochemical media and conditions is crucial to develop versatile, simple and inexpensive fuel cells to develop viable, environmentally friendly, alternative energy sources. Here, we present two new electrochemical media to synthesizemesoporous structures of different metals and alloys in an efficient, easy and fast manner by electrodeposition: surfactant micelles and ionic liquid-in-water (IL/W) microemulsions. We demonstrate the effectiveness of this approach by synthesizing highly mesoporous $\mathrm{lms}$ of different Co-Pt alloys onto Si/Ti $(15 \mathrm{~nm}) / \mathrm{Au}(100 \mathrm{~nm})$ substrates. Moreover, the analysis of theirelectrocatalytic activity for methanol electro-oxidation in alkalinemedia shows not only that these mesoporous Co-Pt alloys are very effective towards this reaction, but they also exhibit a very good stability, in both acidic and alkaline media, and durability. Finally, the magnetic character of the $\operatorname{lms}$ allows them to be easily manipulated by magnetic elds once they are detached from the substrate.

\section{Experimental}

\subsection{Materials.}

Cobalt (II) chloride hexahydrate $-\mathrm{CoCl}_{2} \cdot 6 \mathrm{H}_{2} \mathrm{O}$, Carlo Erba $>98.0 \%$-, sodium hexachloroplatinate (IV) hexahydrate $-\mathrm{Na}_{2} \mathrm{PtCl}_{6} \cdot 6 \mathrm{H}_{2} \mathrm{O}$, Aldrich, $98.0 \%$-, p-octyl poly(ethylene glycol) phenyl ether a.k.a. Triton X-100 - $\mathrm{C}_{14} \mathrm{H}_{22} \mathrm{O}\left(\mathrm{C}_{2} \mathrm{H}_{4} \mathrm{O}\right)_{\mathrm{n}}(\mathrm{n}=9-10)$ Acros Organics, $98 \%$-, Polyethylene glycol hexadecyl ether a.k.a. Brij $58-\mathrm{C}_{16} \mathrm{H}_{33}\left(\mathrm{OCH}_{2} \mathrm{CH}_{2}\right)_{20} \mathrm{OH}$, Sigma -, 1-butyl-3-methylimidazolium hexafluorophosphate aka bmimPF $\mathrm{F}_{6}-\mathrm{C}_{8} \mathrm{H}_{15} \mathrm{~F}_{6} \mathrm{~N}_{2} \mathrm{P}$, Solvionic, $99 \%$ - sodium hydroxide $-\mathrm{NaOH}$, Merck, 99\% -, methanol - $\mathrm{CH}_{3} \mathrm{OH}$, Panreac, $99 \%$-, sulfuric acid - $\mathrm{H}_{2} \mathrm{SO}_{4}$, Sigma, $98 \%$ - and deionized water (Millipore Q-System) with a resistivity of $18.2 \mathrm{M} \Omega \cdot \mathrm{cm}^{-1}$.

\subsection{Electrodeposition.}

The electrochemical fabrication of Pt-based structures (compact, nanopowdered and mesoporous films of $\mathrm{Pt}, \mathrm{Pt}_{3} \mathrm{Co}$ and $\mathrm{Co}_{3} \mathrm{Pt}$ ) was performed by using a microcomputer-controlled potentiostat/galvanostat Autolab (with PGSTAT30 equipment and GPES software) at $25{ }^{\circ} \mathrm{C}$ with a standard three-electrode cell system. Si / Ti $(15 \mathrm{~nm})$ / Au (100 nm) substrates, Pt spiral, and Ag / $\mathrm{AgCl} / 1 \mathrm{M} \mathrm{KCl}$ were used as working, counter, and reference electrodes, respectively. To obtain the three different morphologies (compact, nanopowdered and mesoporous) diverse electrodeposition media were used: (i) aqueous (W), (ii) micellar solutions (M) and (iii) ionic liquid-in-water (IL/W) microemulsions (see Table 1). 
The micellar solutions were prepared by stirring the corresponding aqueous solution for each composition with a non-ionic surfactant (Brij 58) in a 99/1 \% ratio (Table 1) [36-39].

The IL/W microemulsions were prepared by mixing the adequate aqueous solution with a non-ionic surfactant (Triton $\mathrm{X}-100)$ and an ionic liquid $\left(\mathrm{IL},-\right.$ bmimPF $_{6}$ ) in a 83.8/15.1/1.1\% ratio (Table 1) [40-44].

The electrodeposition media were deaerated before each experiment by argon bubbling. The deposition of $\mathrm{Pt}, \mathrm{CoPt}_{3}$ and $\mathrm{Co}_{3} \mathrm{Pt}$ was carried out at fixed potentials of $-0.2,-1.0$ and $-1.1 \mathrm{~V}$, respectively. Note that the electrodeposition was performed without stirring to maintain the structure of each media during the process. After the deposition, the samples were cleaned in methanol and 0.1 $\mathrm{M}$ of $\mathrm{NaOH}$ solution. Afterwards they were thoroughly rinsed with deionized water and finally dried carefully using nitrogen gas.

\begin{tabular}{|c|c|c|c|c|c|}
\hline \multirow{2}{*}{$\begin{array}{l}\text { Electrodeposition } \\
\text { medium }\end{array}$} & & \multirow{2}{*}{\multicolumn{2}{|c|}{ Composition }} & \multicolumn{2}{|l|}{ Deposit } \\
\hline & & & & Composition & Type \\
\hline \multirow{3}{*}{$\begin{array}{l}\text { Aqueous solutions } \\
\text { (W) }\end{array}$} & $\mathrm{W}_{1}$ & \multicolumn{2}{|l|}{$\mathrm{Na}_{2} \mathrm{PtCl}_{6} 20 \mathrm{mM}$} & $\mathrm{Pt}$ & \multirow{3}{*}{$\begin{array}{l}\text { Compact } \\
\text { film }\end{array}$} \\
\hline & $\mathrm{W}_{2}$ & \multicolumn{2}{|l|}{$\mathrm{Na}_{2} \mathrm{PtCl}_{6} 18 \mathrm{mM}$ of $+\mathrm{CoCl}_{2} 2 \mathrm{mM}$} & $\mathrm{CoPt}_{3}$ & \\
\hline & $\mathrm{W}_{3}$ & \multicolumn{2}{|l|}{$\mathrm{Na}_{2} \mathrm{PtCl}_{6} 10 \mathrm{mM}+\mathrm{CoCl}_{2} 10 \mathrm{mM}$} & $\mathrm{Co}_{3} \mathrm{Pt}$ & \\
\hline \multirow{3}{*}{$\begin{array}{l}\text { Micellar solutions } \\
\text { (M) }\end{array}$} & $\mathrm{M}_{1}$ & \multirow{3}{*}{$\begin{array}{l}1.0 \mathrm{wt} . \% \text { of Brij } 58+99.0 \mathrm{wt} . \% \\
\text { of } \mathrm{W}_{\mathrm{i}}\end{array}$} & $\mathrm{W}_{1}$ & $\mathrm{Pt}$ & $\begin{array}{l}\text { Mesoporous } \\
\text { film }\end{array}$ \\
\hline & $\mathrm{M}_{2}$ & & $\mathrm{~W}_{2}$ & $\mathrm{CoPt}_{3}$ & \multirow{2}{*}{$\begin{array}{l}\text { Nano- } \\
\text { powder }\end{array}$} \\
\hline & $\mathrm{M}_{3}$ & & $\mathrm{~W}_{3}$ & $\mathrm{Co}_{3} \mathrm{Pt}$ & \\
\hline \multirow{2}{*}{$\begin{array}{l}\text { Ionic liquid in water } \\
\text { Microemulsions } \\
\text { (IL/W) }\end{array}$} & $\mathrm{IL} / \mathrm{W}_{2}$ & \multirow{2}{*}{$\begin{array}{l}15.1 \text { wt. } \% \text { of Triton } \mathrm{X}-100+ \\
1.1 \text { wt. } \% \text { of } \mathrm{BmimPF}_{6}+83.8 \\
\text { wt. } \% \text { of } \mathrm{W}_{\mathrm{i}}\end{array}$} & $\mathrm{W}_{2}$ & $\mathrm{CoPt}_{3}$ & \multirow{2}{*}{$\begin{array}{l}\text { Mesoporous } \\
\text { film }\end{array}$} \\
\hline & $\mathrm{IL} / \mathrm{W}_{3}$ & & $\mathrm{~W}_{3}$ & $\mathrm{Co}_{3} \mathrm{Pt}$ & \\
\hline
\end{tabular}

Table 1: Electrodeposition media used to obtain the films with different morphologies.

\subsection{Materials characterization}

Field-emission scanning electron microscopy (FE-SEM; Hitachi H-4100FE, $20 \mathrm{kV}$ ) equipped with energy-dispersive X-ray spectroscopy (EDX) was used to analyze the morphology and the elemental composition of the samples. A 3D Optical surface metrology system Leica DCM 3D was used to determine the thickness. X-ray diffraction (XRD) patterns were recorded using a PANalytical X'Pert- 
PRO MRD diffractometer with parallel optical geometry in grazing incidence configuration $\left(1^{\circ}\right)$ using $\mathrm{Cu} \mathrm{K} \alpha$ radiation $(\lambda=0.1542 \mathrm{~nm})$. A $2 \theta$ scan, between 10 and $100^{\circ}$ was used, with a step size of 0.05 and a measuring time of $15 \mathrm{~s}$ per step. Room temperature hysteresis loops were measured using a superconducting quantum interface device (SQUID) magnetometer (Quantum Design MPMS-XL).

\subsection{Electrocatalytic measurements.}

The electrochemical active surface area (ECSA) of the Pt-based structures was estimated by integrating (taking into account the double layer correction [45]) the charge corresponding to the hydrogen adsorption/desorption peaks of the cyclic voltammetry's (CVs) profiles in $0.5 \mathrm{M}^{\circ} \mathrm{H}_{2} \mathrm{SO}_{4}$ solutions, at the scan rate of $100 \mathrm{mV} \cdot \mathrm{s}^{-1}$. From these values, the roughness factor was obtained by dividing the obtained ECSA by the electrode geometric area.

The short-term stability was evaluated by accelerated durability test (ADT) [46], which consist in recording at a scan rate of $100 \mathrm{mV} \cdot \mathrm{s}^{-1}$ in a $1 \mathrm{M}$ of $\mathrm{NaOH}$ solution (working media as a catalyst) for 300 cycles, and then recording at a scan rate of $100 \mathrm{mV} \cdot \mathrm{s}^{-1}$ in $0.5 \mathrm{M}$ of $\mathrm{H}_{2} \mathrm{SO}_{4}$ solution until CVs profile stabilization.

The electrocatalytic activity was investigated using a three-electrode electrochemical cell by $\mathrm{CV}$ measurements, which were performed at $50 \mathrm{mV} \cdot \mathrm{s}^{-1}$ in a $1 \mathrm{M}$ of $\mathrm{NaOH}+1 \mathrm{M}$ of $\mathrm{CH}_{3} \mathrm{OH}$ solutions. The chronoamperometric tests were conducted under the potential of $-0.2 \mathrm{~V}$.

\section{Results and Discussion}

\subsection{Electrochemical synthesis and characterization.}

Co-rich $\left(\mathrm{Co}_{3} \mathrm{Pt}\right)$ and Pt-rich $\left(\mathrm{CoPt}_{3}\right)$ films have been electrodeposited onto $\mathrm{Si} / \mathrm{Ti}(15 \mathrm{~nm}) / \mathrm{Au}(100$ $\mathrm{nm}$ ) substrates using three different electrodeposition media: aqueous solutions (W), micellar solutions (M) or ionic liquid in water (IL/W) microemulsions. The chronoamperograms (Figure 1S in the Supporting Information), in non-stirring conditions, for both aqueous and micellar solution displayed a rapid decay of the initial current, as a consequence of the depletion of the electroactive species near the electrode. However, the posterior gradual moderate rise in current may indicate a slow increase in the active area if, for example, an increase in roughness takes place. The chronoamperograms for IL/W microemulsions showed lower initial current than the previous cases, the posterior decay and a quasi-stationary final current, probably conditioned by the slow transport of electro-active species in the electrodeposition media. In fact, the chronoamperometric curves show that different times are necessary to attain the same deposition charge densities $\left(1.6 \mathrm{C} \mathrm{cm}^{-2}\right)$, i.e., the same amount of material: $\mathrm{W}-275 \mathrm{~s}\left(\mathrm{Co}_{3} \mathrm{Pt}\right) / 279 \mathrm{~s}\left(\mathrm{CoPt}_{3}\right) ; \mathrm{M}-261 \mathrm{~s}\left(\mathrm{Co}_{3} \mathrm{Pt}\right) / 269 \mathrm{~s}\left(\mathrm{CoPt}_{3}\right)$ and 
IL/W - $870 \mathrm{~s}\left(\mathrm{Co}_{3} \mathrm{Pt}\right) / 977 \mathrm{~s}\left(\mathrm{CoPt}_{3}\right)$, respectively. This is expected since the microemulsions used present higher viscosity and lower conductivity than the aqueous or micellar solutions, leading to lower deposition rate. However, although for the IL/W microemulsions medium it take somewhat longer to reach the same amount of material, the differences between media are not substantial, as supported by the similar electrodeposition efficiencies (Table 2), where the electrodeposition efficiencies are determined by the concentration of Co (II) and Pt (IV) in the aqueous component (at the same deposition potential). Note that reference compact and mesoporous Pt films (chronoamperometric curves in Fig. 2Sa) exhibit larger efficiencies (Table 2) since in this case hydrogen evolution is significantly lower at $-0.2 \mathrm{~V}$.

The FE-SEM images show that the electrodeposition media has a dramatic effect on the morphology of the deposited Co-Pt alloys:

(i) Compact films (Fig. 1a, b) were formed when aqueous solutions (W) were used as electrodeposition medium. However, the surface morphology of the Co-Pt deposits was different depending on the stoichiometry of the alloy. The $\mathrm{Co}_{3} \mathrm{Pt}$ one exhibited a distorted acicular morphology, whereas the $\mathrm{CoPt}_{3}$ one show a nodular grained morphology.

(ii) Loosely interconnected nanopowdered deposits (Fig. 1c, d) were obtained in micellar solutions $(\mathrm{M})$, with an average grain size of around $35 \pm 12 \mathrm{~nm}$, for the two Co-Pt stoichiometries.

(iii) Mesoporous films (Fig. 1e, f) were obtained when IL/W microemulsions were used. They are composed of connected structures (Figs. 3S and 4S), with an average pore size of around $42 \pm$ 9 and $35 \pm 7 \mathrm{~nm}$ for $\mathrm{Co}_{3} \mathrm{Pt}$ and $\mathrm{CoPt}_{3}$, respectively, forming a sponge-like structures with high apparent surface areas.

Notably the overall composition of the films remains constant independent of the electrodeposition media: $\mathrm{CoPt}_{3}-\mathrm{Co}_{25 \pm 1} \mathrm{Pt}_{75 \pm 1}$ and $\mathrm{Co}_{3} \mathrm{Pt}-\mathrm{Co}_{75 \pm 2} \mathrm{Pt}_{25 \pm 2}$ (Table 2). 


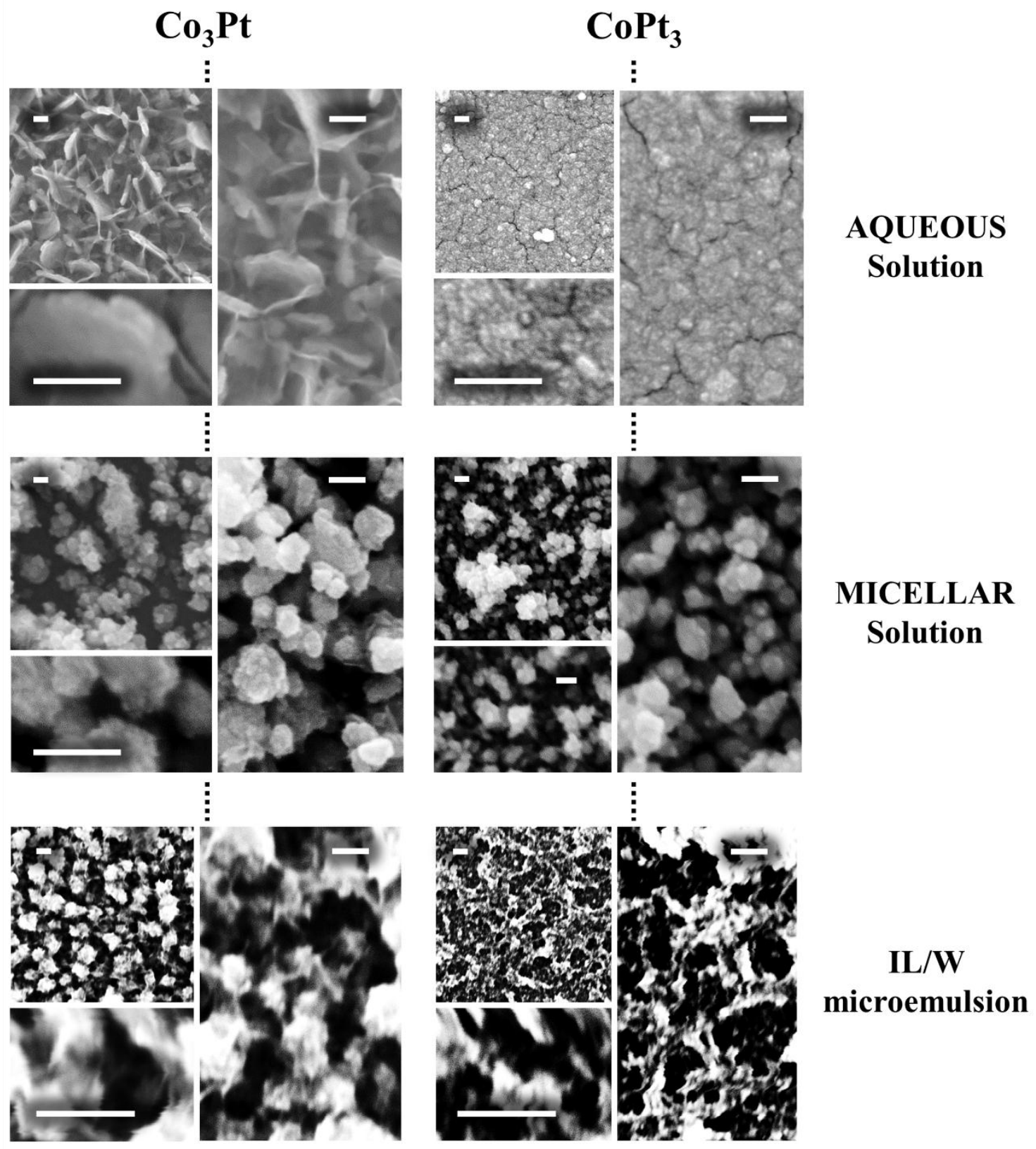

Figure 1: FE-SEM micrographs of Co-Pt structures prepared on $\mathrm{Si} / \mathrm{Ti}(15 \mathrm{~nm}) / \mathrm{Au}(100 \mathrm{~nm})$ substrates using aqueous solutions (a,b), micellar solutions (c,d) or IL/W microemulsion (e,f). Scale bar: $50 \mathrm{~nm}$.

In order to obtain further information on the structure of the material both $\mathrm{Co}_{3} \mathrm{Pt}$ and $\mathrm{CoPt}_{3}$ films were characterized by XRD

To confirm the porosity of the films prepared by IL/W microemulsions the roughness factor of the different films was evaluated from the CVs (Figure 2 and Table 2). Remarkably, the RF values of the 
mesoporous films show a more than 15 -fold increase with respect to the one of the compact films. Moreover, the RF values of the mesoporous films were not only appreciably higher than those of the nanopowder, but more than 30\% larger than the RF of the reference Pt mesoporous films. Thus, the high RF values corroborate the high porosity of the films prepared IL/W microemulsions observed by SEM. Moreover, the RF values of the mesoporous films (with RF > 50) are higher than the previously reported values of other catalysts, such as $2-14$ for Pt-transition metal alloys [23], 45 for mesoporous PtCu films [47] and 3.9 for Pd films [48].

$\mathrm{Co}_{3} \mathrm{Pt}$

(a)

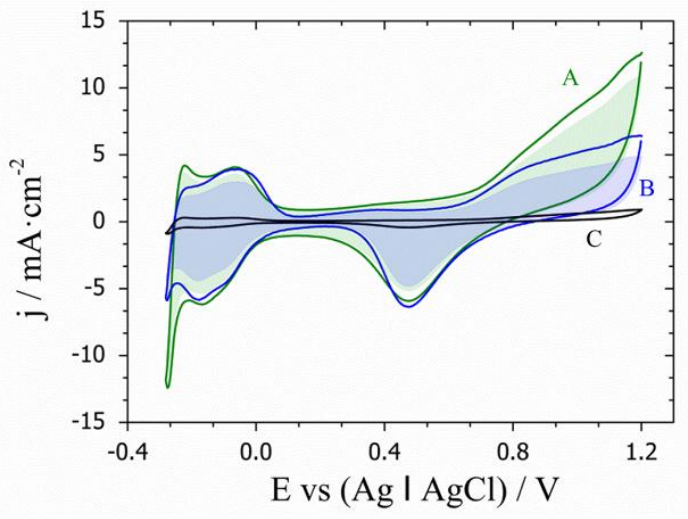

(b)

\section{$\mathrm{CoPt}_{3}$}

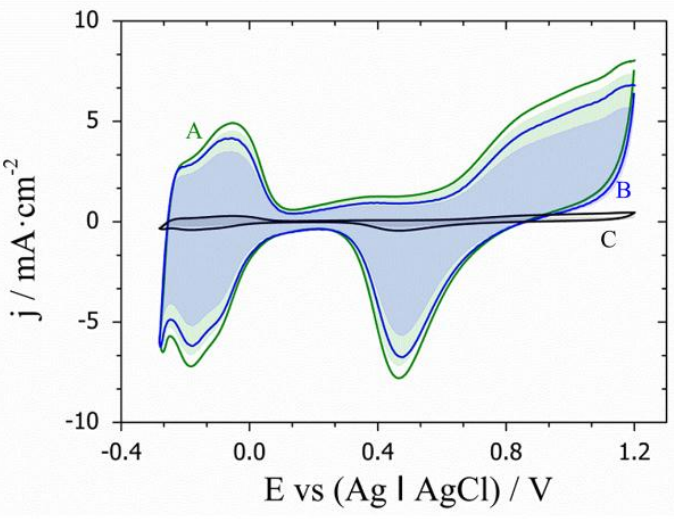

Figure 2: Cyclic voltammetry of Co-Pt compact (C), nanopowdered (B) and mesoporous (A) films in $\mathrm{H}_{2} \mathrm{SO}_{4} 0.5 \mathrm{M}$ solutions at $25^{\circ} \mathrm{C}$ with a scan rate of $100 \mathrm{mV} \mathrm{s}^{-1}$. The line corresponds to the $1^{\text {st }}$ cycle while the coloured area corresponds to the $300^{\text {th }}$ cycle.

Moreover, the durability of the films in basic media is also outstanding. As can be seen in Figure 2 and Table 2, the ECSAs values of each deposit exhibited only a slight decrease after the circulating treatment in an alkaline bath, even in the nanopowder and mesoporous structures. Remarkably, in terms of durability, the ECSA values of the compact and mesoporous Co-Pt alloys were comparable with the reference $\mathrm{Pt}$ deposits (Figure $2 \mathrm{Sb}$ and Supplementary Information) with equivalent morphologies. Additionally, the durability of the mesoporous structures is further confirmed by FESEM (Fig. 7S). Namely, there is no apparent modification of the morphology even after 300 cycles. On the other hand, the nanopowdered and compact samples seem to exhibit certain clustering of the grains after cycling.

\begin{tabular}{|c|c|c|c|c|}
\hline \multirow{2}{*}{$\begin{array}{l}\text { Electrodeposition } \\
\text { media }\end{array}$} & \multirow{2}{*}{$(\mathrm{Co}$ at. $\% / \mathrm{Pt}$ at. $\%)$} & \multirow{2}{*}{$\begin{array}{l}\text { Deposition } \\
\text { Efficiency }\end{array}$} & \multicolumn{2}{|c|}{ ECSA/RF } \\
\hline & & & $1^{\text {st }}$ cycle & $300^{\text {th }}$ cycle \\
\hline
\end{tabular}




\begin{tabular}{|c|c|c|c|c|}
\hline & & $\varepsilon / \%$ & & \\
\hline \multirow{3}{*}{ Aqueous Solution } & $\mathrm{Pt}$ & 68 & $2.4 / 2.4$ & 2.3 \\
\hline & $\mathrm{Co}_{3} \mathrm{Pt}(77 / 23)$ & 26 & 3.8 & 3.6 \\
\hline & $\mathrm{CoPt}_{3}(24 / 76)$ & 19 & 3.3 & 3.1 \\
\hline \multirow{3}{*}{ Micellar solution } & $\mathrm{Pt}$ & 69 & 40 & 37 \\
\hline & $\mathrm{Co}_{3} \mathrm{Pt}(75 / 25)$ & 25 & 49 & 44 \\
\hline & $\mathrm{CoPt}_{3}(25 / 75)$ & 20 & 46 & 42 \\
\hline \multirow{2}{*}{$\begin{array}{l}\text { IL/W } \\
\text { microemulsion }\end{array}$} & $\mathrm{Co}_{3} \mathrm{Pt}(74 / 26)$ & 19 & 54 & 50 \\
\hline & $\mathrm{CoPt}_{3}(27 / 73)$ & 17 & 58 & 55 \\
\hline
\end{tabular}

Table 2: Elemental composition, electrodeposition efficiencies ( $\boldsymbol{\varepsilon})$, and electrochemical active surface area (ECSA) / roughness factor (RF) of the different Co-Pt structures.

Notably, previous studies have shown that water-in-ionic liquid (W/IL) microemulsions, in semistirring conditions, were useful systems for preparing mesoporous materials [40, 41]. However, the high viscosity and low conductivity of these systems require deposition times approximately 30 times higher than the required time to attain the same deposition charge in aqueous solution. This fact limits a practical use of the water-in-ionic liquid (W/IL) microemulsions as an efficient methodology for preparing mesoporous structures [40, 41]. In contrast, we demonstrate that ionic liquid-in-water (IL/W) microemulsions involve significantly lower depositions times and higher efficiencies in comparison with the W/IL systems. This significant improvement arises from the high proportion of the electrolytic aqueous solution in the IL/W microemulsion, which favors an effective deposition rate. On the other hand, the presence of IL drops in the solution induces the formation of the pores. The reduced deposition time, the high porosity and excellent durability make electrodeposition in IL/W microemulsions a new realistic, exceptionably efficient approach to prepare mesoporous films of any metallic material by an easy and environmentally friendly procedure. In fact, the nature of the synthesis method, makes this approach easily applicable to other metals and alloys.

Another appealing feature of the mesoporous alloys prepared by IL/W microemulsions is that they can be detached form the substrate relatively easily. For sufficiently thick films (higher than $200 \mathrm{~nm}$ ) fragments of the mesoporous deposited material readily loosen from the substrate during the growth. Alternatively, for thinner films, other methods (like thermal shock, see Figure 5S) can be used to free the mesoporous material. Interestingly, the possibility to conveniently separate the mesoporous structures from the substrate opens the door to a new route to prepare freestanding mesoporous structures. 
Moreover, in the particular case of $\mathrm{CoPt}_{3}$ and $\mathrm{Co}_{3} \mathrm{Pt}$, all the studied films, in particular the mesoporous ones, are magnetic at room temperature (see Supplementary Information). It has been shown that the use of magnetic nano-catalysts is rather attractive since it facilitates the remote manipulation using magnetic fields $[49,50]$. Indeed, as shown Figure 5S, their magnetic character allows the easy handling of the materials with a laboratory magnet once they are detached from the substrate.

\subsection{Electrocatalytic performance of Co-Pt structures.}

The electrocatalytic performance of the Co-Pt structures as possible fuel cells was evaluated by the methanol oxidation reaction (see Fig. 3 -normalized by the ECSAs values- and Fig. $6 \mathrm{~S}$-normalized by the geometrical area of working electrodes-). The CVs profiles exhibit an irreversible oxidation peak in the forward scan, which is associated with the oxidation of freshly chemisorbed methanol, accompanied by the appearance of another anodic peak in the reverse scan attributed to the oxidation of the adsorbed intermediates species produced during the forward scan (Fig. 3a,b). Importantly, the fact that the oxidation peak appears at negative potential $\left(E_{p}-\right.$ Table 3$)$ for the Co-Pt mesoporous films indicates an excellent catalytic activity for methanol electro-oxidation. Moreover, the negatively shift in the onset potential ( $E_{\text {onset }}$ - Table 3) compared with the reference Pt structures, in the same experimental conditions, shows an obvious improvement in the kinetics of the methanol electrooxidation, due to synergistic effect of both the mesoporous morphology and the cobalt content [48]. Similarly, the peak current densities of methanol oxidation in the forward $\left(j_{f}\right)$ and reverse $\left(j_{b}\right) s c a n s$ for the mesoporous films are much higher than those on the nanopowder and compact films catalysts. Actually, it is important to note that the activity of the Co-Pt mesoporous films is also higher than that reported in state-of-art of platinum films, such as Pt disks [49] or Pt shell films [50]. The origin of the enhanced activity arises from the fact that mesoporous or nanopowder morphologies provide a concave metal surface, which offers abundant rich edges and corner atoms that are active sites for the electro-oxidation of methanol.

Moreover, it is worth emphasizing that the chronoamperometric curves recorded at $0.5 \mathrm{~V}$ for $7200 \mathrm{~s}$ (Fig. 4c and d) indicate that the current density of mesoporous and nanopowder morphologies for both Co-Pt stoichiometries was higher than that of compact $\square$ lms in the entire time range, demonstrating good stability of the catalytic performance. Finally, the turnover number (TON), which is dened as the number of methanolmolecules that react per catalyst surface site, was also calculated in order to compare the catalytic efficiency of each catalyst.59,60 As shown in Fig. 4c and d, the current density a $\square$ er 6500 s could be considered to be the steady-state current density, and then the TON was calculated according to eqn (1): TON molecules per site $\quad \mathrm{P}^{1 / 4} \mathrm{j}$ js _ 6:02 _ $1023 \mathrm{nF} \_1: 3{ }_{-} 1015(1)$ 
where jss is the steady-state current density a er the 6500 s process, $n$ is the number of electrons produced by the oxidation of 1 mol of methanol (n $1 / 46), F$ is the Faraday constant, and the density of the topmost atoms of an ideal $\operatorname{Pt}(100)$ surface is about $1.3 \_1015$ cm_2. The TON values (at_0.5 V), summarized in Table 3, demonstrate the viability of both Co-Pt mesoporous and nanopowder morphologies, as they can oxidize more methanol per second with the same number of sites than compact structures or Pt $\square \mathrm{lms}$. Moreover, the presence of Co drastically increases the catalytic efficiency of the lms.

$\mathrm{Co}_{3} \mathrm{Pt}$

(a)

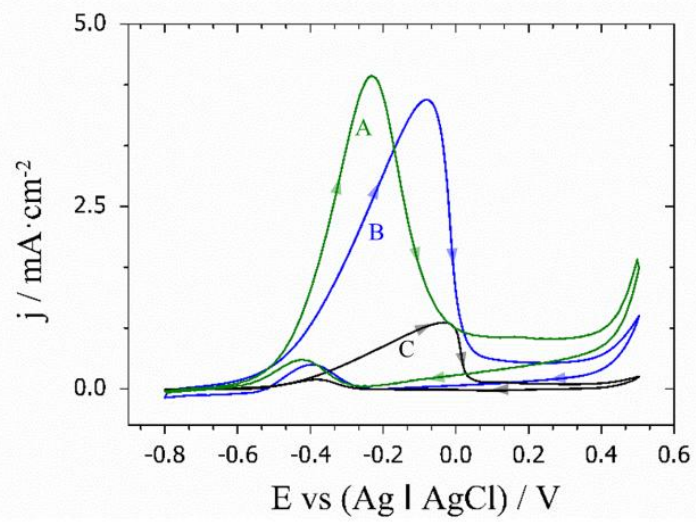

(c)

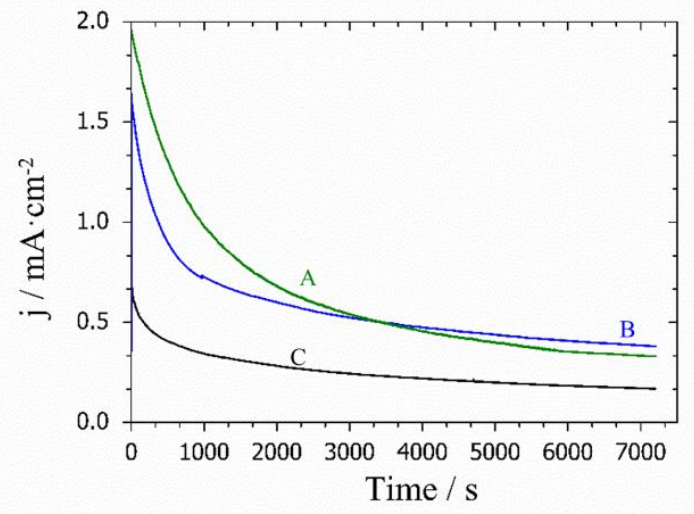

$\mathrm{CoPt}_{3}$

(b)

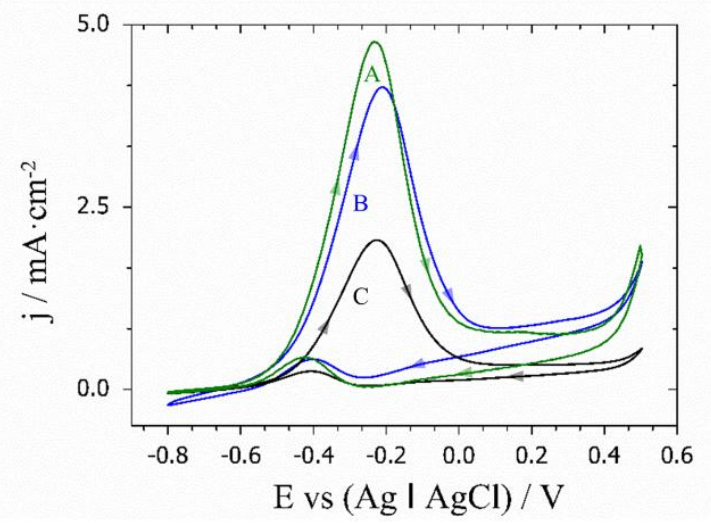

(d)

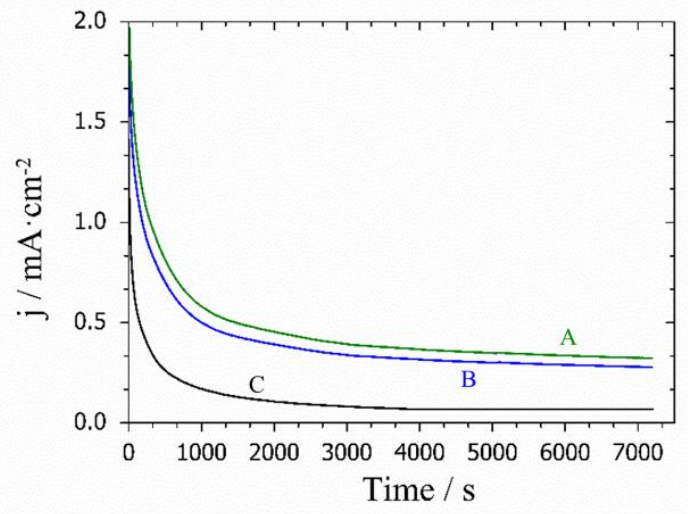

Figure 4: Cyclic voltammograms (normalized by their ECSA values) at $50 \mathrm{mV} \mathrm{s}^{-1}$ (a, b) and chronoamperometric curves recorded at $-0.5 \mathrm{~V}(\mathrm{c}, \mathrm{d})$ of Co-Pt compact (C), nanopowdered (B) and mesoporous (A) films in $1 \mathrm{M}$ of $\mathrm{NaOH}+1 \mathrm{M}$ of $\mathrm{CH}_{3} \mathrm{OH}$.

Table 2: Catalysis characterization and catalytic performance of different Co-Pt films.

\begin{tabular}{|l|l|l|l|l|l|l|}
\hline Electrodeposition & & Pt / at. \% & $\mathbf{E}_{\text {onset }} / \mathbf{V}$ & $\mathbf{j}_{\mathrm{f}} / \mathbf{m A ~} \mathbf{~ c m}^{-2}$ & $\mathbf{E}_{\mathrm{p}} / \mathbf{V}$ & $\mathbf{j}_{\mathrm{f}} / \mathbf{j}_{\mathrm{b}}$ \\
\hline
\end{tabular}




\begin{tabular}{|c|c|c|c|c|c|c|}
\hline media & & & & & & \\
\hline \multirow{2}{*}{ Aqueous Solution } & $\mathrm{Pt}$ & 100 & -0.523 & 0.4 & -0.094 & 2.1 \\
\hline & $\mathrm{Co}_{3} \mathrm{Pt}$ & 23 & -0.568 & 0.9 & -0.048 & 8.1 \\
\hline Compact & $\mathrm{CoPt}_{3}$ & 76 & -0.572 & 2.0 & -0.224 & 8.0 \\
\hline Micellar solution & $\mathrm{Pt}$ & 100 & -0.584 & 2.8 & 0.005 & 2.9 \\
\hline \multirow{2}{*}{$\begin{array}{l}\text { Nanopowder } \\
(\mathrm{CoPt}) \\
\text { Mesoporous }(\mathrm{Pt})\end{array}$} & $\mathrm{Co}_{3} \mathrm{Pt}$ & 25 & -0.765 & 4.0 & -0.084 & 12.1 \\
\hline & $\mathrm{CoPt}_{3}$ & 75 & -0.717 & 4.1 & -0.209 & 10.3 \\
\hline \multirow{2}{*}{$\begin{array}{l}\mathrm{IL} / \mathrm{W} \\
\text { microemulsion }\end{array}$} & $\mathrm{Co}_{3} \mathrm{Pt}$ & 74 & -0.722 & 4.3 & -0.223 & 10.8 \\
\hline & $\mathrm{CoPt}_{3}$ & 27 & -0.739 & 4.8 & -0.229 & 12.0 \\
\hline Mesoporous & & & & & & \\
\hline
\end{tabular}

\section{CONCLUSIONS}

In summary, mesoporous Co-Pt $\square$ lms with different stoichiometries (Co3Pt and CoPt3) have been obtained by a highly efficient electrodeposition approach based on ionic liquid-in water microemulsions. The mesoporous structures do not only present a high degree of porosity, but also excellent stability and durability in both acid and alkaline media. The diverse lms are magnetic and can be detached from the substrate, allowing theeasy manipulation by magnetic elds. Interestingly, the mesoporous $1 \mathrm{~ms}$ exhibit an enhanced catalytic activity towards methanol oxidation under alkaline conditions, with exceptional stability and low catalyst poisoning. Thus, their outstandingcatalytic performance and the fast, simple, inexpensive and environmentally friendly synthesis procedure make these structures excellent candidates for the commercial exploitation of direct methanol fuel cells. 


\section{ACKNOWLEDGMENT}

This work was supported by the EU ERDF (FEDER) fund and the Spanish Government grant TEC2014-51940-C2-2-R from Ministerio de Economía y Competitividad (MINECO). The partial support from the 2014-SGR-1015 project from the Generalitat de Catalunya and the Russian grants RFBR 16-02-00058 and RG14.B25.31.0025 is also acknowledged. A. S. thanks the Ministeriode Educacion, Cultura y Deporte for a predoctoral grant (FPU). The authors thank the CCiT-UB for the use of their equipment. ICN2 acknowledges support from the Severo Ochoa Program (MINECO, Grant SEV-2013-0295).

\section{References}

1 J.-M. Tarascon and M. Armand, Nature, 2001, 414, 359.

2 N. Quintana, F. V. Van der Kooy, M. D. Van de Rhee, G. O. Voshol and R. Verpoorte, Appl. Microbiol. Biotechnol., 2011, 91, 471.

3 Y. Shao, J. Sui, G. Yin and Y. Gao, Appl. Catal., B, 2008, 79, 89.

4 M. K. Debe, Nature, 2012, 486, 43.

5 S. H. Joo, S. J. Choi, I. Oh, J. Kwak, Z. Liu, O. Terasaki and R. Ryoo, Nature, 2001, 412, 169.

6 J. Duan, Y. Zheng, S. Chen, Y. Tang, M. Jaroniec and S. Z. Qiao, Chem. Commun., 2013, 49, 7705 .

7 C. Shang, W. Hong, J. Wang and E. Wang, J. Power Sources, 2015, 285, 12.

8 J. Duan, X. Zhang, W. Yuan, H. Chen, S. Jiang, X. Liu, Y. Zhang, L. Chang, Z. Sun and J. Du, J. Power Sources, 2015, 285, 76.

9 Y. K. Su, H. Liu, M. Feng, Z. L. Yan, Z. H. Cheng, J. N. Tang and H. T. Yang, Electrochim. Acta, 2015, 161, 124.

10 H. A. Gasteiger, S. S. Kocha, B. Sompalli and F. T. Wagner, Appl. Catal., B, 2005, 56, 9.

11 L. Su, S. Shrestha, Z. Zhang, W. Mustain and Y. Lei, J. Mater. Chem. A, 2013, 1, 12293.

12 J.-S. Zheng, T. Tian, Y. Gao, Q. Wu, J.-X. Ma and J.-P. Zheng, Int. J. Hydrogen Energy, 2014, 39, 13816.

13 B. Bilizanac, P. Ross and N. Markovik, Electrochim. Acta, 2007, 52, 2264.

14 J. S. Spendelow and A. Wieckowski, Phys. Chem. Chem. Phys., 2007, 9, 2654.

15 L. Zhu, T. Zhao, J. Xu and Z. Ling, J. Power Sources, 2009, 187, 80.

16 C. T. Carver, B. D. Matson and J. M. Mayer, J. Am. Chem. Soc., 2012, 134, 5444. 
17 Z. W. Chen, D. Higgins, A. P. Yu, L. Zhang and J. J. Zhang, Energy Environ. Sci., 2011, 4, 3167 .

18 R. A. Sidik and A. B. Anderson, J. Phys. Chem. B, 2006, 110, 936-941.

19 D. Susac, L. Zhu, M. Teo, A. Sode, K. C. Wong, P. C. Wong, R. R. Parsons, D. Bizzotto, K. A. R. Mitchell and S. A. Campbell, J. Phys. Chem. C, 2007, 111, 18715.

20 M. D. Obradovic, U. C. Lacnjevac, B. M. Babic, P. Ercius, V. R. Radmilovic, N. V. Krstajic and S. L. Gojkovi, Appl. Catal., B, 2015, 170-171, 144. 21 S. Sharma and B. G. Pollet, J. Power Sources, 2012, 208, 96.

22 K. Mohanraju, V. Sreejith, R. Ananth and L. Cindrella, J. Power Sources, 2015, 284, 383.

23 V. G. Khomenko, V. Z. Barsukov and A. S. Katashinskii, Electrochim. Acta, 2005, 50, 1675.

24 A. A. Ensa $\square$, M. Jafari-Asl, B. Rezaei, M. M Abarghoui and H. Farrokhpour, J. Power Sources, 2015, 282, 452.

25 S.-S. Li, J.-J. Lv, Y.-Y. Hu, J.-N. Zheng, J.-R. Chen, A.-J. Wang and J.-J. Feng, J. Power Sources, 2014, 247, 213.

26 N. Wakabayashi, M. Takeichi, H. Uchida and M. Watanabe, J. Phys. Chem. B, 2005, 109, 5836.

27 C. T. Kresge, M. E. Leonowicz, W. J. Roth, J. C. Vartuli and J. S. Beck, Nature, 1992, $359,710$.

28 J. S. Beck, J. C. Vartuli, W. J. Roth, M. E. Leonowicz, C. T. Kresge, K. D. Schmitt, C. T. W. Chu, D. H. Olson, E. W. Sheppard, S. B. McCullen, J. B. Higgins and J. L. Schlenker, J. Am. Chem. Soc., 1992, 114, 10834.

29 E. S. Toberer, T. D. Schladt and R. Seshadri, J. Am. Chem. Soc., 2006, 128, 1462.

30 Y. Ren, Z. Ma, R. E. Morris, Z. Liu, F. Jiao, S. Dai and P. G. Bruce, Nat. Commun., 2013, 4, 2015.

31 Z. C. Bai, B. Sun, N. Fan, Z. C. Ju, M. H. Li, L. Q. Xu and Y. T. Qian, Chem.-Eur. J., $2012,18,5319$.

32 H. B. Wu, H. Pang and X. W. Lou, Energy Environ. Sci., 2013, 6, 3619.

33 P. Rekha, V. Sharma and P. Mohanty, Microporous Mesoporous Mater., 2016, 219, 93.

34 Z. Wu, Q. Li, D. Feng, P. A. Webley and D. Zhao, J. Am. Chem. Soc., 2010, 132, 12042.

35 G. S. Attard, S. A. A. Leclerc, S. Maniguet, A. E. Russell, L. Nandhakumar and P. N. Bartlett, Chem. Mater., 2001, 13, 1444.

36 X. Zhang, W. Lu, J. Dai, L. Bourgeois, N. Hao, H. Wang, D. Zhao and P. A. Webley, Angew. Chem., Int. Ed., 2010, 122, 10299. 
37 M. Cabo, E. Pellicer, E. Rossinyol, M. Estrader, A. Lopez-Ortega, J. Nogués, O. Castell, S. Surĩnach and M. D. Baro, J. Mater. Chem., 2010, 20, 7021.

38 M. A. Ghanem, A. M. Al-Mayouf, J. P. Singh, T. Abiti andF. Marken, J. Electrochem. Soc., 2015, 162, 453.

39 C. Li, T. Sato and Y. Yamauchi, Angew. Chem., Int. Ed., 2013, 125, 8208.

40 C. Li, V. Malgras, S. M. Alshehri, J. H. Kim and Y. Yamauchi, Electrochim. Acta, 2015, $183,107$.

41 J. Z. Wang, Y. Zhao and C.-B. Zhang, Acta Phys.-Chim. Sin., 2003, 19, 251.

42 A. E. C. Palmqvist, Curr. Opin. Colloid Interface Sci., 2003, 8, 145.

43 C. Li, V. Malgras, A. Aldabahi and Y. Yamauchi, Chem.-Asian J., 2015, 10, 316.

44 M. E. Abdelsalam, S. Mahajan, P. N. Bartlett, J. J Baumberg and A. E. Russell, J. Am. Chem. Soc., 2007, 129, 7399.

45 A. Serr`a, E. G’omez and E. Vall’es, Int. J. Hydrogen Energy, 2015, 40, 8062.

46 A. Serr`a, E. G’omez and E. Vall'es, Electrochim. Acta, 2015, 174, 630.

47 H. Gao, J. Li, B. Han, W. Chen, J. Zhang, J. Zhang and D. Yan, Phys. Chem. Chem. Phys., 2004, 6, 2914.

48 H. Gao, S. Han, B. Han, G. Li, D. Shen, Z. Li, J. Du, W. Hou and G. Zhang, Langmuir, 2005, 21, 5681 .

49 A. Serrà, E. Gómez, J. F. L’opez-Barbera, J. Nogués and

E. Vallés, ACS Nano, 2014, 8, 4630.

50 J. Rodriguez-Carvajal, Phys. B, 1993, 192, 55.

51 N. Tian, Z.-Y. Zhou, S.-G. Sun, Y. Ding and L. W. Zhong, Science, 2007, 316, 732.

52 D.-H. Lim, D.-H. Choi, W.-D. Lee and H.-I. Lee, Appl. Catal., B, 2009, 89, 484.

53 D. Weller, H. Brändle, G. Gorman, C. J. Lin and H. Notarys, Appl. Phys. Lett., 1992, 61, 2726.

54 G. Herzer, IEEE Trans. Magn., 1990, 26, 1397.

55 G. G. W. Lee, J. Leddy and S. D. Minteer, Chem. Commun., 2012, 48, 11972.

56 N. Atar, T. Eren, M. L. Yola, H. Karimi-Maleh and B. Demird“ogen, RSC Adv., 2015, 5, 26402.

57 W. Huang, H. Wang, J. Zhou, J. Wang, P. N. Duchesne, D. Muir, P. Zhang, N. Han, F. Zhao, M. Zeng, J. Zhong, C. Jin, Y. Li, S.-T. Lee and H. Dai, Nat. Commun., 2016, 6, 10035. 58 J.-N. Zheng, S.-S. Li, X. Ma, F.-Y. Chen, A.-J. Wang, J.-R. Chen and J.-J. Feng, J. Mater. Chem. A, 2014, 2, 8386.

59 Y. Lei, G. Zhao, X. X. Tong, M. Liu, D. Li and R. Geng, ChemPhysChem, 2010, 11, 276. 
60 W. Ye, H. Kou, Q. Liu, J. Yan, F. Zhou and C. Wang, Int. J. Hydrogen Energy, 2012, 37, 4088. 